\title{
On the monitoring of the vibratory environment of DCMIX4 campaign. Preliminary results
}

\author{
D. Dubert ${ }^{1}$, M. Marín-Genescà2 ${ }^{2}$, M. J. Simón ${ }^{2}$, J.M. Ezquerro ${ }^{3}$, Jna. Gavaldà ${ }^{1}$, X. Ruiz ${ }^{1,4}$, V. Shevtsova ${ }^{5}$ \\ ${ }^{1}$ Universitat Rovira i Virgili, Departament de Química Física i Inorgànica, Tarragona, Spain; ${ }^{2}$ Universitat Rovira i Virgili, Departament \\ d'Enginyeria Mecànica, Tarragona, Spain; ${ }^{3}$ E-USOC. ETSIAE Universidad Politécnica de Madrid, Madrid, Spain; ${ }^{4}$ Institut d'Estudis \\ Espacials de Catalunya, IEEC, Barcelona. Spain; ${ }^{5}$ Department of Chemical Physics, MRC, Université Libre Bruxelles, Bruxelles, Belgium. \\ dianacristina.dubert@urv.cat, marc.marin@urv.cat, mariajose.simon@urv.cat,jm.ezquerro@upm.es, fina.gavalda@urv.cat
}

, josepxavier.ruiz@urv.cat, vshev@ulb.ac.be

\section{Introduction}

In the framework of the European Space Agency, all campaigns of the program called "Diffusion and Thermodiffusion Coefficients Measurements in Ternary Mixtures (DCMIX)" aim to accurately measure pure diffusion, thermodiffusion and Soret coefficients of different, but technologically relevant, ternary liquid systems (Shevtsova et al 2014, Triller et al 2018) inside the International Space Station (ISS).

Due to the own nature of the physical processes implied, molecular diffusion and thermodiffusion experiments take a long time, therefore, a careful monitoring of the vibrational environment is thus of capital importance to prevent spurious results potentially related to detectable disturbances occurred during the experiments (Jurado et al 2016, Ollé et al 2017, Dubert et al 2018). Based on this, the present work focused on the preliminary characterization of the DCMIX4 accelerometric environment taking into account the signals coming from the es09006 sensor, nearest to the experiment. The raw accelerometric signals, with a sampling rate of 142 $\mathrm{Hz}$ and a cut-off frequency of $6 \mathrm{~Hz}$, were freely downloaded from PIMS NASA website (PIMS website: PIMS 2019). Therefore the signal characterization focuses on the low frequency range which it is known to be the most harmful for the thermodifussion experiments (Shevtsova et al. 2015). DCMIX4 experiments were performed in five different cells with different mixtures and component concentrations. The first three cells run with the DCMIX2 mixture at different concentrations while cell 4 and 5 run with tetralin-toluene-fullerene and polystyrene-toluene-hexane, respectively. The campaign consisted of 49 runs lasting between 12 and 48 hours. Remark that in the first experiments of each cell, acceleration data are unavailable, due to the malfunction of the sensor. Consequently, it has been analized only the runs in which the sensor was switched on. In addition, all the runs had a missing period data when passing from one day to another. In other words, the signal's recording was always stopped during 10 minutes after midnight.

\section{Metodology, results and discussion}

Digital signal processing techniques were systematically applied minute by minute to all the signals, covering both the typical time and frequency analyses: the Root Mean Square (RMS), the Power Spectral Density (PSD), Spectral ENtropy (SEN) and the warning maps (see more details in Ollé et al 2017, Dubert et al 2018). The run 2r07 has been selected as an exemple for the applied techniques.

Fig 1 plots the calculated global RMS values along the whole experiment for the selected run. During the 16 hours of the experiment, two noticeable spikes can be observed. Time domain warnings could be associated to these peaks, therefore the experimentalists should take them into account when interpreting the experimental results. A spike can be considered a warning if its RMS value exceeds the $20 \%$ of the mean of all RMS values of the signal (Ollé et al 2017). More details of the spikes found are presented in Table 2.

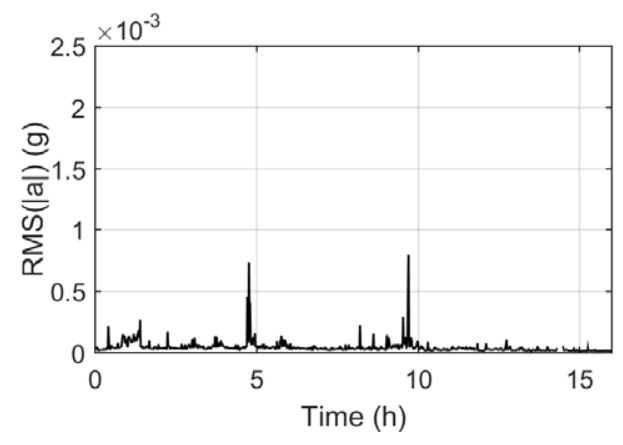

Figur e 1: Glob al RMS (run 2r07)

RMS warni ng map technique is a quick visual way to display if the vibratory limits have been surpassed or not, along the experiment. The map plots the frequency bands on the $\mathrm{X}$ axis and the experiment's duration on Y axis. Symbols in the RMS warning map represent each of the ISS vibratory limits that were exceeded.

To illustrate the above considerations, Fig. 2.a displays the RMS values of the three acceleration components in one-third-octave frequency intervals of the selected signal, calculated for the minute 400. Figure 3.b plots the warning map along all the experiment. 
It can be seen that RMS values are quite close to the limit curve below $1 \mathrm{~Hz}$, crossing it at frequency ranges $0.17-0.28$ and $0.45-0.58 \mathrm{~Hz}$ in $\mathrm{x}_{\mathrm{A}}$ and $\mathrm{y}_{\mathrm{A}}$ directions, respectively. Moreover, the ISS limit requirements are outdo for almost the entire duration of the experiment and in all three directions, if low frequencies ranges, below $0.6 \mathrm{~Hz}$ are considered (see Fig 3.b). Table 1 summarizes the frequency bands that outdo the

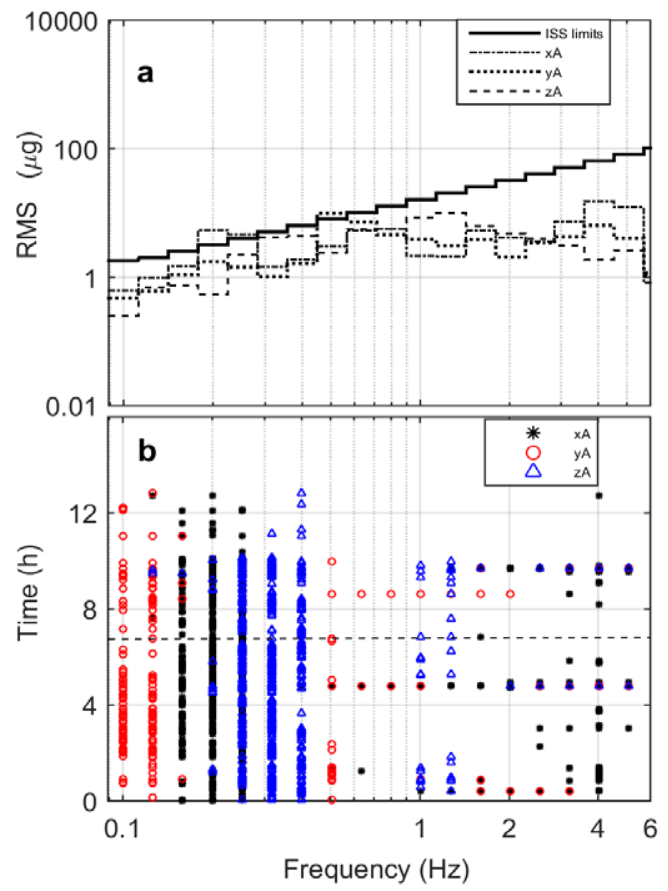

ISS limits for all the completed runs.

Figure 2: a) RMS acceleration components vs. one third octave frecuency bands calculated in the minute $400, \mathrm{~b}$ ) Marks indicating when the RMS exceeds the ISS limit curve requirements (Run 2r07).

Table 1: Vibrational observations

\begin{tabular}{|c|c|c|}
\hline \multirow[b]{2}{*}{ Run } & \multicolumn{2}{|c|}{ Vibrational environmental observations } \\
\hline & $\begin{array}{c}\text { Time domain } \\
\text { (time where there are } \\
\text { RMS spikes, } \mathrm{h} \text { ) }\end{array}$ & $\begin{array}{c}\text { Frequency domain } \\
\text { (range that exceeds the ISS } \\
\text { limits, Hz) }\end{array}$ \\
\hline \multicolumn{3}{|c|}{ Cell \#1: Toluene-Methanol-Cyclohexane $(0.20-0.25-0.55 \mathrm{wt} \%)$} \\
\hline $1 \mathrm{r} 04$ & Small RMS peaks & $0.2-0.3$ \\
\hline $1 \mathrm{r} 05$ & $27.05 \mathrm{~h}$ & $0.2-0.3$ \\
\hline $1 \mathrm{r} 06$ & Small RMS peaks & $0.17-0.35$ \\
\hline 1r07 & $\begin{array}{c}16.57 \mathrm{~h}, 33.1 \mathrm{~h}, 33.3 \mathrm{~h}, \\
34.1 \mathrm{~h}, 34.45 \mathrm{~h}\end{array}$ & Correct \\
\hline $1 \mathrm{r} 08$ & $13.93 \mathrm{~h}, 16.74 \mathrm{~h}$ & $0.22-0.28$ \\
\hline \multicolumn{3}{|c|}{ Cell \#2: Toluene-Methanol-Cyclohexane $(0.35-0.25-0.40$ wt\%) } \\
\hline $2 \mathrm{r} 06$ & Correct & $0.28-0.35$ \\
\hline $2 \mathrm{r} 07$ & $4.758 \mathrm{~h}, 9.692 \mathrm{~h}$ & $0.17-0.35$ \\
\hline $2 \mathrm{r} 08$ & Small RMS peaks & $0.22-0.35$ \\
\hline $2 \mathrm{r} 09$ & Correct & Correct \\
\hline $2 \mathrm{r} 10$ & $11.04 \mathrm{~h}, 12.19 \mathrm{~h}$ & Correct \\
\hline $2 \mathrm{r} 11$ & Correct & $0.22-0.28$ \\
\hline $2 \mathrm{r} 12$ & $5.542 \mathrm{~h}$ & Correct \\
\hline \multicolumn{3}{|c|}{ Cell \#3: Toluene-Methanol-Cyclohexane $(0.55-0.25-0.20$ wt\%) } \\
\hline $3 \mathrm{r} 08$ & Correct & $0.22-0.28$ \\
\hline
\end{tabular}

\begin{tabular}{|c|c|c|}
\hline $3 \mathrm{r} 09$ & $0.525 \mathrm{~h}, 0.608 \mathrm{~h}, 8.525 \mathrm{~h}$ & $0.17-0.35$ \\
\hline $3 \mathrm{r} 10$ & Correct & Correct \\
\hline $3 \mathrm{r} 11$ & Correct & Correct \\
\hline $3 \mathrm{r} 12$ & Correct & $0.22-0.28$ \\
\hline $3 \mathrm{r} 14$ & $0.125 \mathrm{~h}$ & $0.22-0.28 \mathrm{HZ}$ \\
\hline \multicolumn{3}{|c|}{$\begin{array}{l}\text { Cell \#4: Tetrahydronaphthalene-Toluene-Fullerene }\left(\begin{array}{lll}0.60 & -0.3993- \\
0.0007 & \text { wt } \%)\end{array}\right.\end{array}$} \\
\hline $4 \mathrm{r} 04$ & Correct & $0.22-0.28$ \\
\hline $4 \mathrm{r} 05$ & $15.55 \mathrm{~h}$ & $0.22-0.28$ \\
\hline $4 \mathrm{r} 06$ & $9.986 \mathrm{~h}$ & $0.17-0.35$ \\
\hline $4 \mathrm{r} 07$ & $17.54 \mathrm{~h}, 19.92 \mathrm{~h}$ & $0.17-0.35$ \\
\hline $4 \mathrm{r} 08$ & $\begin{array}{c}1.508 \mathrm{~h}, 7.925 \mathrm{~h}, 20.69 \mathrm{~h}, \\
23.67 \mathrm{~h}\end{array}$ & $0.22-0.28$ \\
\hline \multicolumn{3}{|c|}{ Cell \#5: Polystyrene-Toluene-n-Hexane $(0.02-0.49-0.49$ wt \%) } \\
\hline $5 \mathrm{r} 03$ & $\begin{array}{c}6.408 \mathrm{~h}, 30.41 \mathrm{~h}, 31 \mathrm{~h}, \\
31.01 \mathrm{~h},\end{array}$ & $0.17-0.35$ \\
\hline $5 \mathrm{r} 04$ & $13.84 \mathrm{~h}$ & $0.17-0.35$ \\
\hline
\end{tabular}

\section{Conclusions}

A preliminary accelerometric characterization of the microgravity environment of DCMIX4 runs was performed, enabling further evaluation of its potential impact on the experimental results.

\section{Acknowledgements}

The present work has been supported by grants ESP2017-83544-C3-1-P (MCIU/FEDER) and 2018PFR-URV-B2-73 (Rovira I Virgili University).

\section{References}

D. Dubert, J. Ollé, R. Jurado, Jna. Gavaldà, A. Laverón-Simavilla, X. Ruiz and V. Shevtsova, Characterization of the accelerometric environment of DCMIX2/3 experiments; Microgravity Science and Technology, 30 (2018) 683-697.

https://pims.grc.nasa.gov/html/ISSAccelerationArchive.html R. Jurado, M.J. Simón, J. Pallarés, A. Laverón-Simavilla, X. Ruiz and V. Shevtsova; Some considerations on the vibrational environment of the DSC-DCMIX1 experiment onboard ISS. Acta Astronautica, 129 (2016) 345-356.

J. Ollé, D. Dubert, Jna. Gavaldà, A. Laverón-Simavilla, X. Ruiz and V. Shevtsova; Onsite vibrational characterization of DCMIX2/3 experiments. Acta Astronautica, 140 (2017) 409-419.

V. Shevtsova, C. Santos, V. Sechenyh, J.C. Legros, A. Mialdun; Diffusion and Soret in Ternary Mixtures. Preparation of the DCMIX2 Experiment on the ISS. Microgravity Sci Tech. 25 (2014) 275-283.

V. Shevtsova, Y. Gaponenko, V. Sechenyh, D. Melnikov; Dynamics of a binary mixture subjected to a temperature gradient and oscillatory forcing. Journal of Fluid Mechanics 767 (2015) 290-322.

T. Triller, H. Bataller, M.M. Bou-Ali, M. Braibanti, F. Croccolo, J.M. Ezquerro, Q. Galand, Jna. Gavaldà, E. Lapeira, A. Laverón-Simavilla, T. Lyubimova, A. Mialdun, J.M. Ortiz de Zárate, J. Rodrínguez, X. Ruiz, I. Ryzhkov, V. Shevtsova, S. Van Vaerenbergh, W. Köhler; Thermodiffusion in ternary mixtures of water/ethanol/triethylene glycol: first report on the DCMIX3-experiments performed on the International Space Station. Microgravity Sci. Technol, 30(3) (2018) 295-308. 